\title{
Microstrip Based Pressure Sensor Antenna for Harsh Environment Applications
}

Muhabaw Amare Alebachew ( $\nabla$ muhabawa4@gmail.com )

Debre Tabor University

Anil Kumar Nayak

IIT Roorkee: Indian Institute of Technology Roorkee

Amalendu Patnaik

IIT Roorkee: Indian Institute of Technology Roorkee

\section{Research Article}

Keywords: microstrip antenna, pressure sensor, sensing at a distance

Posted Date: November 17th, 2021

DOI: https://doi.org/10.21203/rs.3.rs-1076378/v1

License: (c) (1) This work is licensed under a Creative Commons Attribution 4.0 International License.

Read Full License 


\section{Abstract}

this paper is studied on a microstrip based pressure sensor for harsh environment applications which can sensing at a distance. A microstrip based pressure sensor for harsh environment was investigated with good results by using Rogers's 3210 substrate material with a dielectric constant of $10.2,1.28 \mathrm{~mm}$ thickness and $2.4 \mathrm{GHz}$ resonant frequency, and also both the patch side and the ground side are made from copper metal. The simulation of a proposed antenna was designed and tested by using HFSS software, the result of the designed antenna's resonance frequency is inversely proportional with the displacement gap of the reflection plate and an antenna. The operating principles of this sensor, when a pressure (load) is applied on the reflection metal plate, the distance will decrease from the reflection plate and the resonant frequency will increase. Therefore, the applied pressure (load) can determined by measuring the changing resonance frequencies. Certainly, the simulation and the experimental results of performances and validates are clearly discussed.

\section{Introduction}

Pressure sensor is one of the sensor system technology which has a wide role to controlling and mentoring a daily activities of environment conditions. It has the a lot of advantages in different technologies, such as industrial technology, biomedical technology, military system, ionizing radiation, chemical exposure and other various technologies. Pressure sensor parameter measurement in real time for different applications has great significant to be safe, effective and long term operation. Most pressure sensors are wired (physically connected) sensors which cannot be applied in different applications. Wired pressure sensors have a power consumption factor that restricts the performance of the sensor. However, wireless technology becomes the modern research direction for various sensor research area. Since wireless sensors are easy to install, have long service life and no power consumption [1]-[3].

There are different types of pressure sensors which are commonly used, such as resonant pressure sensor, piezo resistive pressure sensor, and capacitive pressure sensor e.t.c. Most of these pressure sensors are used a diaphragm which reflects in response to pressure sensor reversal and also it can used to measure pressure at particular directions, such as liquid pressure and air pressure measurement. But, most sensors are wired and physically connected to take measurement of a pressure, so these sensors cannot be functional for all pressure problems specially at high pressure and also wired pressure sensors are limited in application [1], [4].

That is why now wireless pressure sensor technologies are developing to answer the limited functionalities of wired sensors and also have long life service life. Since, due to their compact size, passivity material, low cost, long life service life and non-power consumption, many wireless passive pressure sensors are developing. Such as Inductor and capacitor (LC) resonant pressure sensor, microwave scattering-type pressure sensor and so on [5]-[7]. For instance, in piezo resistive pressure sensor, the applied pressure sensor could varies the resistance of a sensor, which can be changed over to 
a voltage yield utilizing an extension circuit and then the pressure can be measured from the output voltage [8]. And also in capacitance pressure sensor measurement technique, when capacitive sensor is carry out toward a resistor-capacitor (RC) oscillator and the pressure- induced capacitance difference makes the produced frequency shifted, then the applied pressure can determined by measuring the frequency shift [9].

In this work, a pressure sensor, which contains a microstrip antenna and a copper reflected metal plate was proposed. When the pressure is enforced to the metal plate, then the gap between a microstrip antenna and a reflected plate will scale down, which shifts the resonant frequency of an antenna and then the applied pressure will be determined.

\section{Principle Operation Of Pressure Sensor}

As shown in figure 1, the pressure sensor contains a R03210 substrate of microstrip antenna with a copper metal and a copper plate metal which is putting above the antenna. When the frequency signal is radiated by the microstrip antenna some signals could be deflected back by the metal plate to the antenna, then the reflected signal will change the resonant frequencies of the designed antenna. When the pressure is applied on the metal plate, the distance between the antenna and the metal plate slightly will be change. Therefor the resonant frequency of the antenna will change when the gap between metal plate and antenna will change. Then through calculating the shifted resonant frequency, the enforced pressure will determined.

\section{Antenna Design For Pressure Sensor}

The designed antenna is a microstrip antenna by using R03210 substrate material for pressure sensor system. For this work, R03210 is used as a substrate material to connect the ground with patch and a copper metal used as a ground and a patch. The antenna is design on a single R03210 substrate with dielectric constant of 10.2, thickness $1.28 \mathrm{~mm}$ and feed by a $50 \Omega$ microstrip lines. As shown in figure 2 , the slot parts used as an enhancement of gain. All the simulations are carried out by using high frequency structure simulator (HFSS).

Table 1: Parameters and its value used for antenna design 


\begin{tabular}{|lll|}
\hline Name the parameter & Symbol of parameter & Value \\
\hline Thickness of substrate & $h$ & $1.28 \mathrm{~mm}$ \\
\hline Ground width & Ws & $47 \mathrm{~mm}$ \\
\hline Ground Length & Ls & $45 \mathrm{~mm}$ \\
\hline Patch Width & W & $26.8 \mathrm{~mm}$ \\
\hline Patch Length & L & $19.34 \mathrm{~mm}$ \\
\hline Width of feed 1 & Wf1 & $1.25 \mathrm{~mm}$ \\
\hline Length of Feed 1 & Lf1 & $8 \mathrm{~mm}$ \\
\hline Width of feed 2 & Wf2 & $5 \mathrm{~mm}$ \\
\hline Length of Feed 2 & Lf2 & $7 \mathrm{~mm}$ \\
\hline The height of the plate from Antenna & Hp & $60 \mathrm{~mm}$ \\
\hline Thickness of the plate & Tp & $2 \mathrm{~mm}$ \\
\hline Width of Slot & SW & $1.5 \mathrm{~mm}$ \\
\hline Length of Slot & SL & $3 \mathrm{~mm}$ \\
\hline Radius of the circle & R & $1 \mathrm{~mm}$ \\
\hline
\end{tabular}

\section{Result And Discussion}

\section{Simulation result}

The characteristics of microstrip antenna radiation can be expressed by the parameters reflection coefficient (S11), which defined as a return loss as a function of the designed antenna resonant frequency. This resonant frequency is a frequency at the minimum return loss value which exists in the figure 3. As shown in the figure the reflection coefficient of the design antenna is $-21.895 \mathrm{~dB}$ at a resonant frequency of $2.4009 \mathrm{GHz}$.

The maximum gain capability for the proposed antenna is $2.10 \mathrm{~dB}$ with a narrow band width.

\section{Experimental result}

A fabricated design was an integrating of microstrip antenna sensor and reflection plate. For testing a fabricated antenna, a 3D modeled plastic material and two foam product supporters were used, as shown in the figure. Acrylonitrile Butadiene Styrene (ABS) material is a plastic material which used in this work to protect the bending of reflection plate (to increase the strength of reflection plate) when pressure is applied on a plate. The two foam materials were used as a flexible supporter; when pressure is applied on 
the reflection plate, the two flexible foams will be compressed, and after pressure is removed, they will take the first position. When the RF signal is radiated by the microstrip antenna some signals may be deflected back by the metal plate to the antenna, then the deflected signal can change the resonant frequencies of the designed antenna.

For this experimental work, I use the weight of an object as pressure to apply on the reflection plate instead of pressure.

When the weight is applied on the reflection plate, the gap between an antenna and a reflection plate will decrease and the resonant frequency will increase. So a weight which is applied on the reflection plate has forward relation with resonant frequency as displayed in figure.

The experimental reflection coefficient (return loss) of microstrip antenna is $-15.986 \mathrm{~dB}$ at resonant frequency of $2.395 \mathrm{GHz}$ in figure 7. The experimental resonant frequency is a frequency at which the minimum return loss value will exist before applied any pressure.

As shown in the figure 8, instead of pressure when $4.7236 \mathrm{~N}$ weight is applied on the reflection plate the resonant frequency is shift to $2.725 \mathrm{GHz}$ with return loss of $-19.755 \mathrm{db}$.

As shown in the figure 9 , when $6.1838 \mathrm{~N}$ weight is applied on the reflection plate the resonant frequency is shift to $2.83 \mathrm{GHz}$ with return loss of $-19.00 \mathrm{db}$.

As shown in the figure 10, when $6.2916 \mathrm{~N}$ weight is applied on the reflection plate the resonant frequency is shift to $2.85 \mathrm{GHz}$ with return loss of $-17.36 \mathrm{db}$.

As shown in the figure 11, when $7.2618 \mathrm{~N}$ weight is applied on the reflection plate the resonant frequency is shift to $2.95 \mathrm{GHz}$ with return loss of $-22.10 \mathrm{db}$.

As shown in figure 13 , the retun loss of simulation is -21.89 at $2.4009 \mathrm{GHz}$ resonant frequency and the return loss of an experiment is -15.986 at $2.395 \mathrm{GHz}$ resonant frequency. The experimental result has some differences with the simulation result, because of the experimental supportive material of $A B S$ plastic material has more than a unity dielectric constant.

\section{Conclusion}

A microstrip based pressure sensor for harsh environment was investigated with good results by using R03210 substrate material with a dielectric constant of $10.2,1.28 \mathrm{~mm}$ thickness and $2.4 \mathrm{GHz}$ resonant frequency, and also both the patch side and the ground side are made from copper metal. The simulation of a proposed antenna was designed and tested by using HFSS software, the result of the designed antenna's resonance frequency is proportional with the downward gap of the reflection plate and an antenna. The operating principles of this sensor, when a pressure (load) is applied on the reflection metal plate, the distance will decrease from the reflection plate and the resonant frequency will increase. 
Therefore, the applied pressure (load) can determined by measuring the changing resonance frequencies.

\section{Declarations}

\section{Conflict of interest}

We here submitted the manuscript entitled "Microstrip based pressure sensor antenna for harsh environment applications" to be considered for publication. We declare that this is our original research work.

There is no conflict of interest between authors.

\begin{tabular}{|llll|}
\hline No. & Name of Author & Affiliation & E-mail \\
\hline 1 & Muhabaw Amare Alebachew & Debre Tabor University & muhabawa4@gmail.com \\
\hline 2 & Anil Kumar Nayak & IIT Roorkee & anayak@ec.iitr.ac.in \\
\hline 3 & Pro. Amalendu Patnaik & IIT Roorkee & amalendu.patnaik@ece.iitr.ac.in \\
\hline
\end{tabular}

Funding requirements: There is no funding

\section{Acknowledgment}

I would like to thanks to my co-authors their helpfulness, suggestions, encouragement, guidance and support from the initial to the final of my work, to know different simulation software and to develop deep understanding of this work.

\section{References}

[1] Y. J. Guo, Q. L. Tan, F. Lu, G. Z. Wu, and L. Zhang, "A wireless passive pressure sensor based on aperture coupled microstrip patch antenna," Sens. Rev., vol. 38, no. 2, pp. 156-162, 2018, doi: 10.1108/SR-05-2017-0076.

[2] W. N. Wang and Q. Fan, "Tire pressure monitoring system and wireless passive surface acoustic wave sensor," Appl. Mech. Mater., vol. 536-537, pp. 333-337, 2014, doi: 10.4028/www.scientific.net/AMM.536-537.333.

[3] A. Kim, C. R. Powell, and B. Ziaie, "An Universal packaging technique for low-drift implantable pressure sensors," Biomed. Microdevices, vol. 18, no. 2, 2016, doi: 10.1007/s10544-016-0058-y.

[4] B. Kubina, M. Schusler, C. Mandel, A. Mehmood, and R. Jakoby, "Wireless high-temperature sensing with a chipless tag based on a dielectric resonator antenna," Proc. IEEE Sensors, pp. 8-11, 2013, doi: 10.1109/ICSENS.2013.6688181. 
[5] H. Cheng et al., "Evanescent-mode-resonator-based and antenna-integrated wireless passive pressure sensors for harsh-environment applications," Sensors Actuators, A Phys., vol. 220, pp. 22-33, 2014, doi: 10.1016/j.sna.2014.09.010.

[6] Q. Tan et al., "Antenna-resonator integrated wireless passive temperature sensor based on lowtemperature co-fired ceramic for harsh environment," Sensors Actuators, A Phys., vol. 236, pp. 299-308, 2015, doi: 10.1016/j.sna.2015.10.052.

[7] H. Huang, "Flexible wireless antenna sensor: A review," IEEE Sens. J., vol. 13, no. 10, pp. 3865-3872, 2013, doi: 10.1109/JSEN.2013.2242464.

[8] S. Chen, M. Q. Zhu, B. H. Ma, and W. Z. Yuan, "Design and optimization of a micro piezoresistive pressure sensor," 3rd IEEE Int. Conf. Nano/Micro Eng. Mol. Syst. NEMS, pp. 351-356, 2008, doi: 10.1109/NEMS.2008.4484350.

[9] D. Crescini, V. Ferrari, D. Marioli, and A. Taroni, "A thick-film capacitive pressure sensor with improved linearity due to electrode-shaping and frequency conversion," Meas. Sci. Technol., vol. 8, no. 1, pp. 71-77, 1997, doi: 10.1088/0957-0233/8/1/010.

\section{Figures}

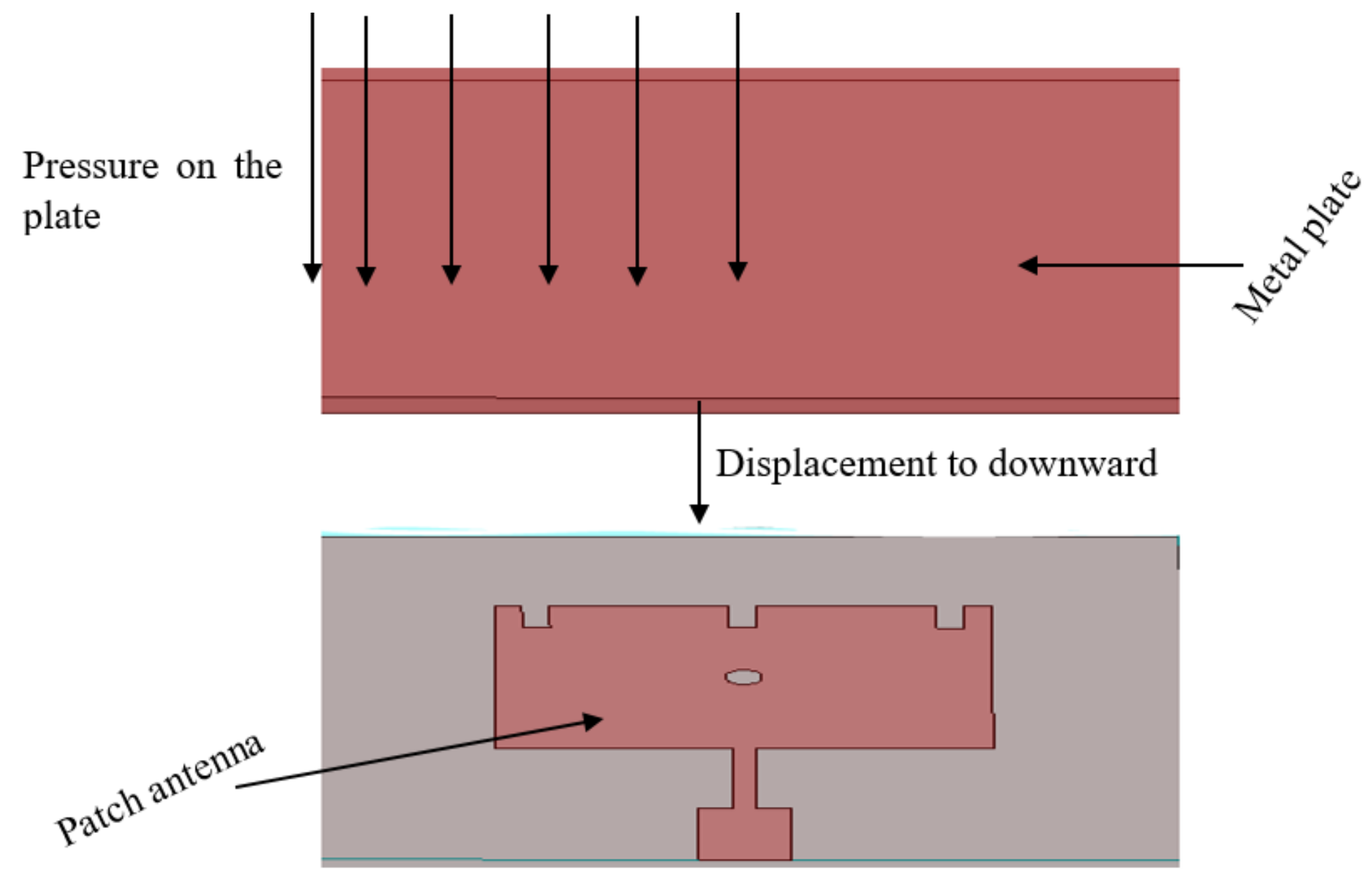


Figure 1

Microstrip Antenna for pressure sensor

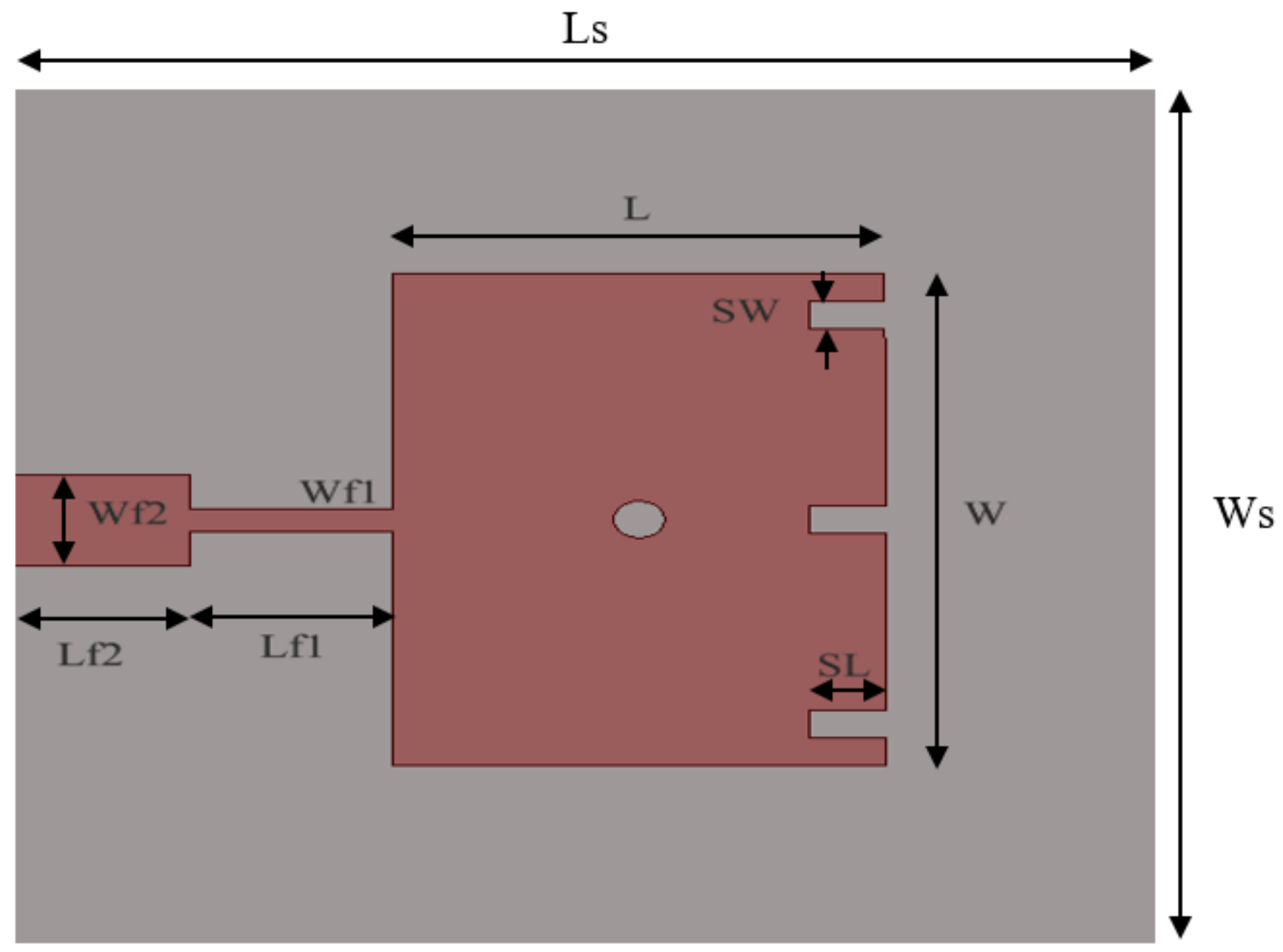

Figure 2

Pressure sensor antenna 


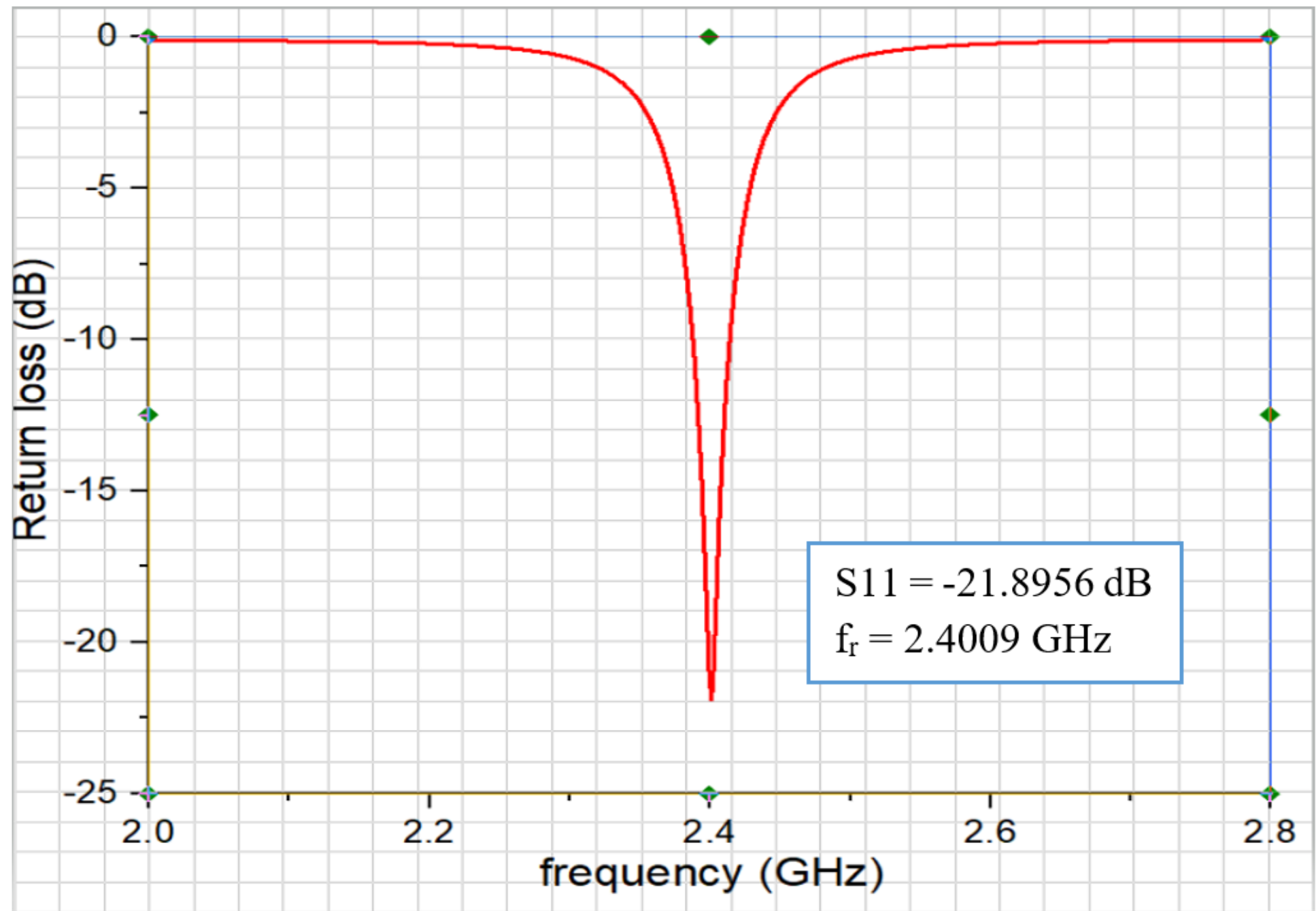

Figure 3

Reflection coefficient of microstrip antenna 


\section{Gain Plot 1}

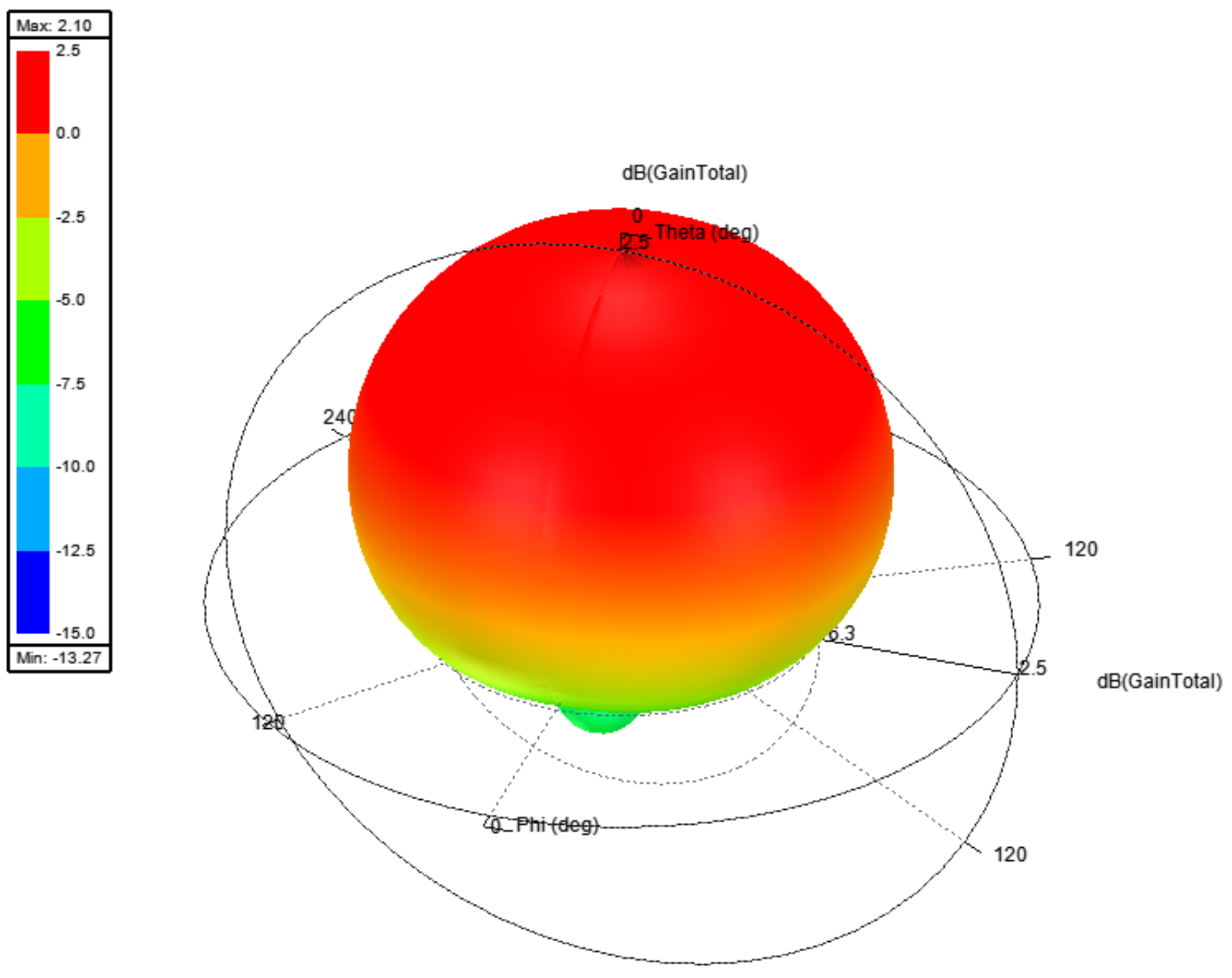

Figure 4

Gain of microstrip antenna based pressure sensor 


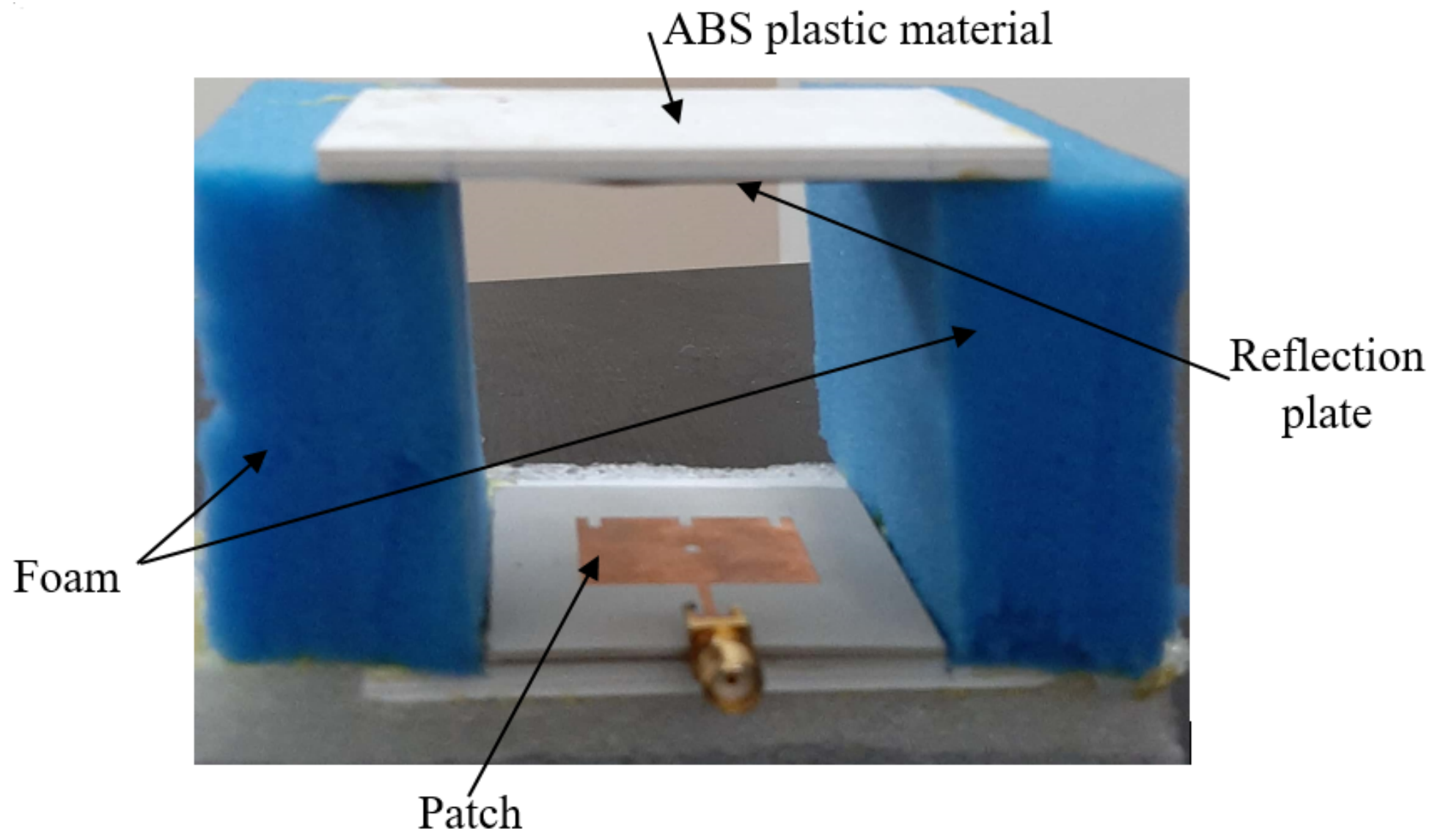

Figure 5

Fabricated antenna for pressure sensor 


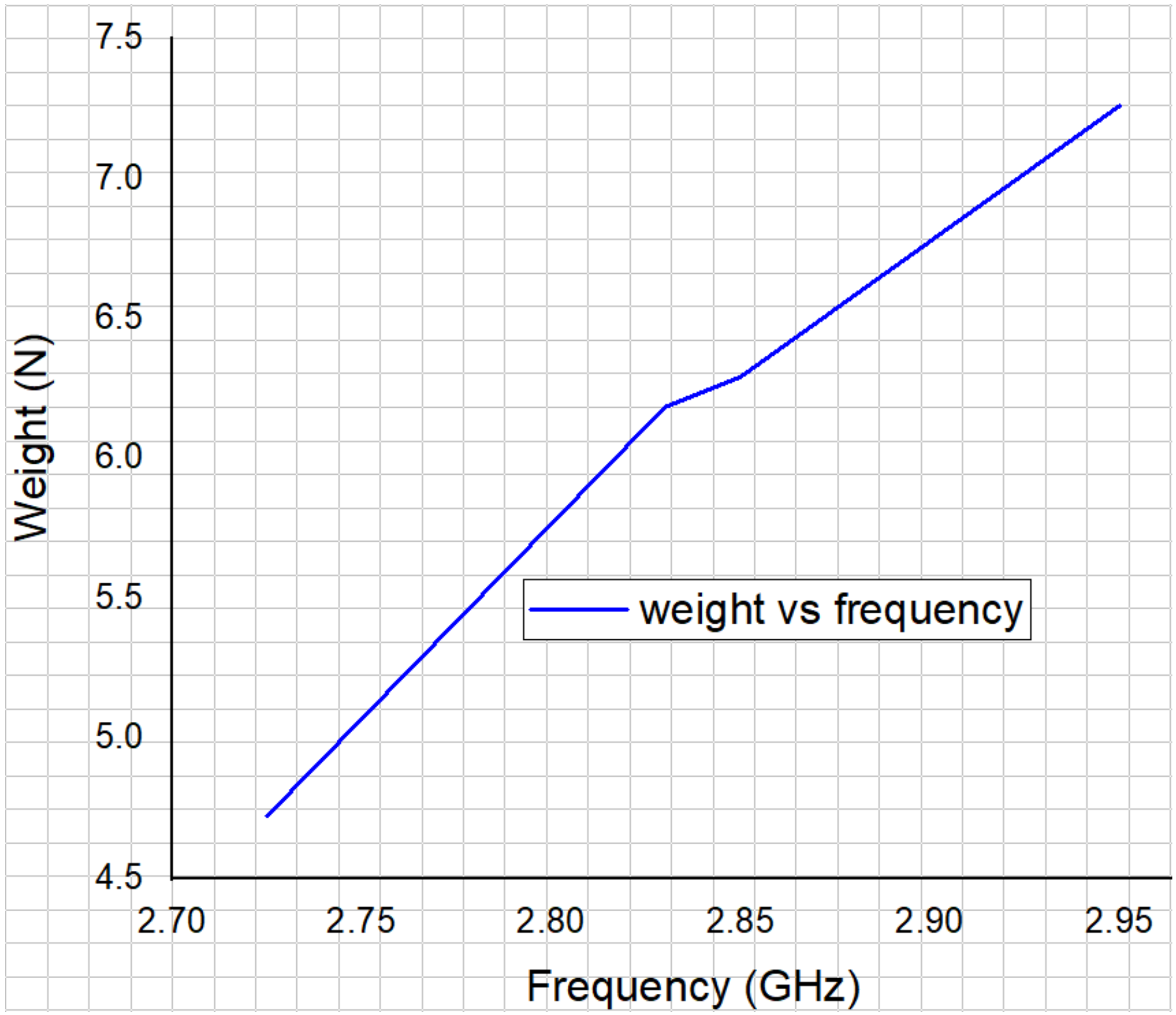

Figure 6

Characteristics of weight vs frequency graph 

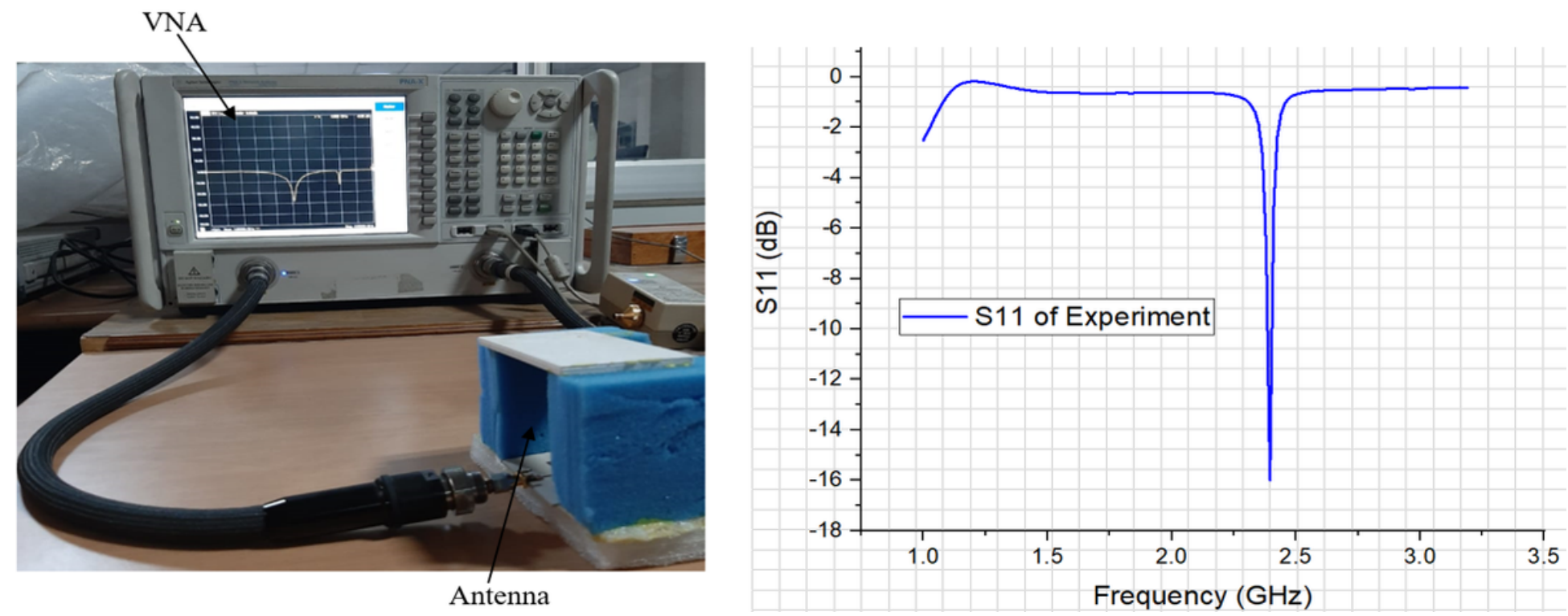

Figure 7

The schematic diagram of fabricated antenna for pressure sensor

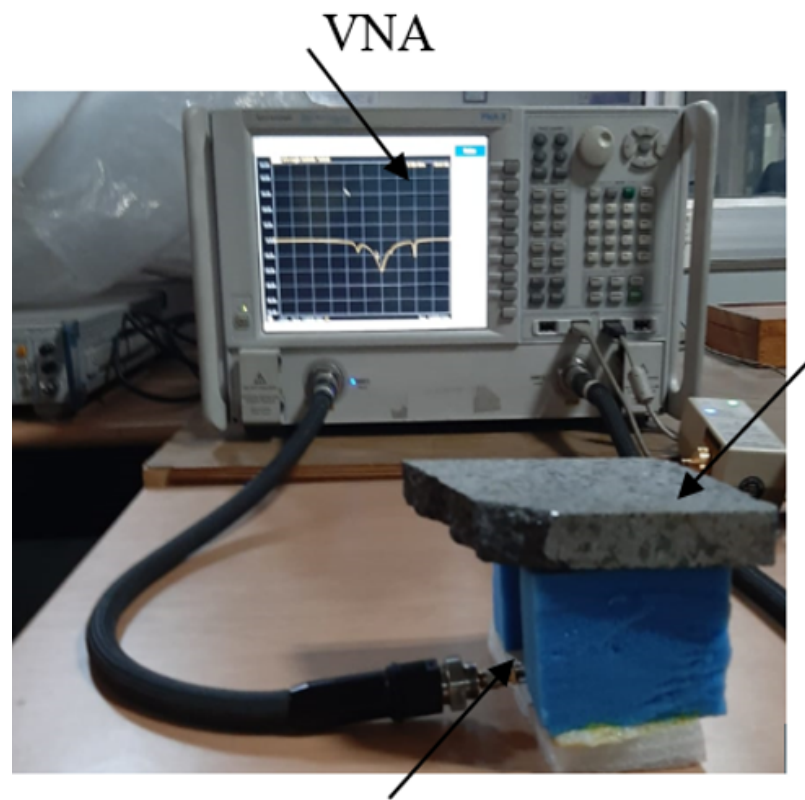

Pressure sensor antenna

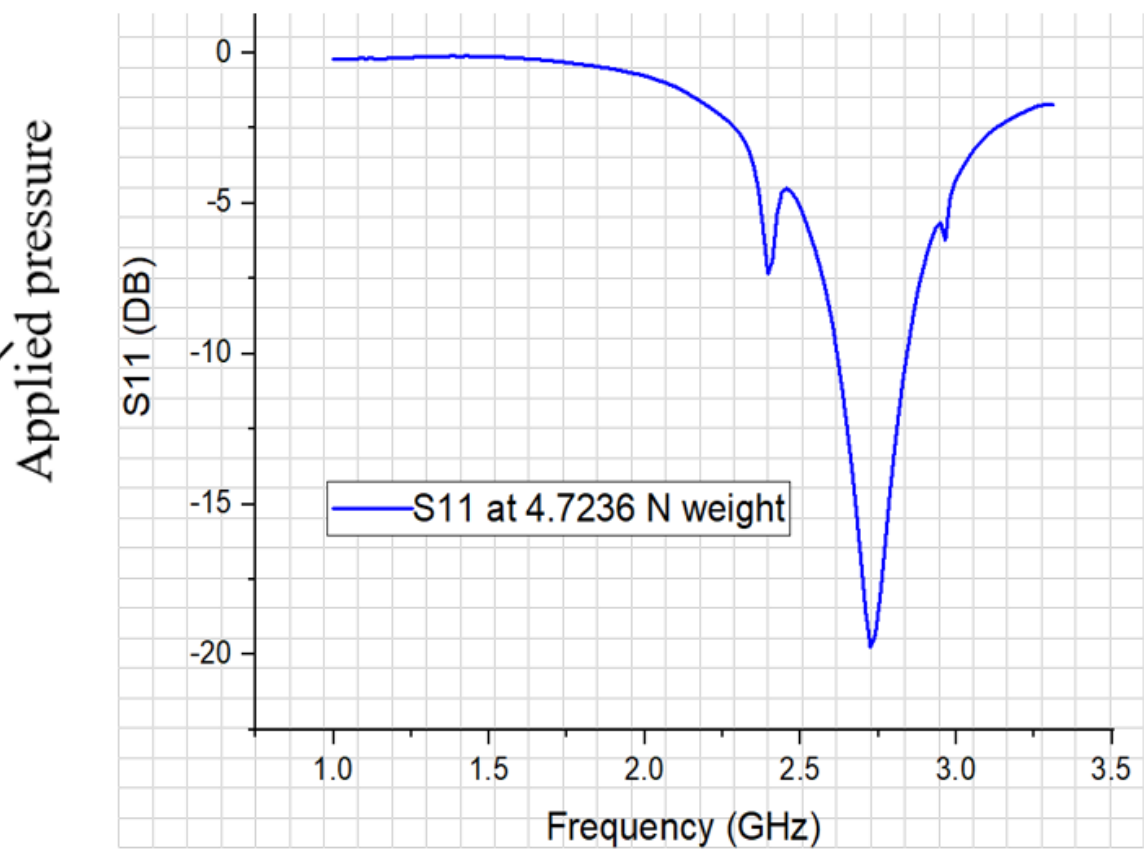

Figure 8

Experimental reflection coefficient when $4.7236 \mathrm{~N}$ weight load is applied 

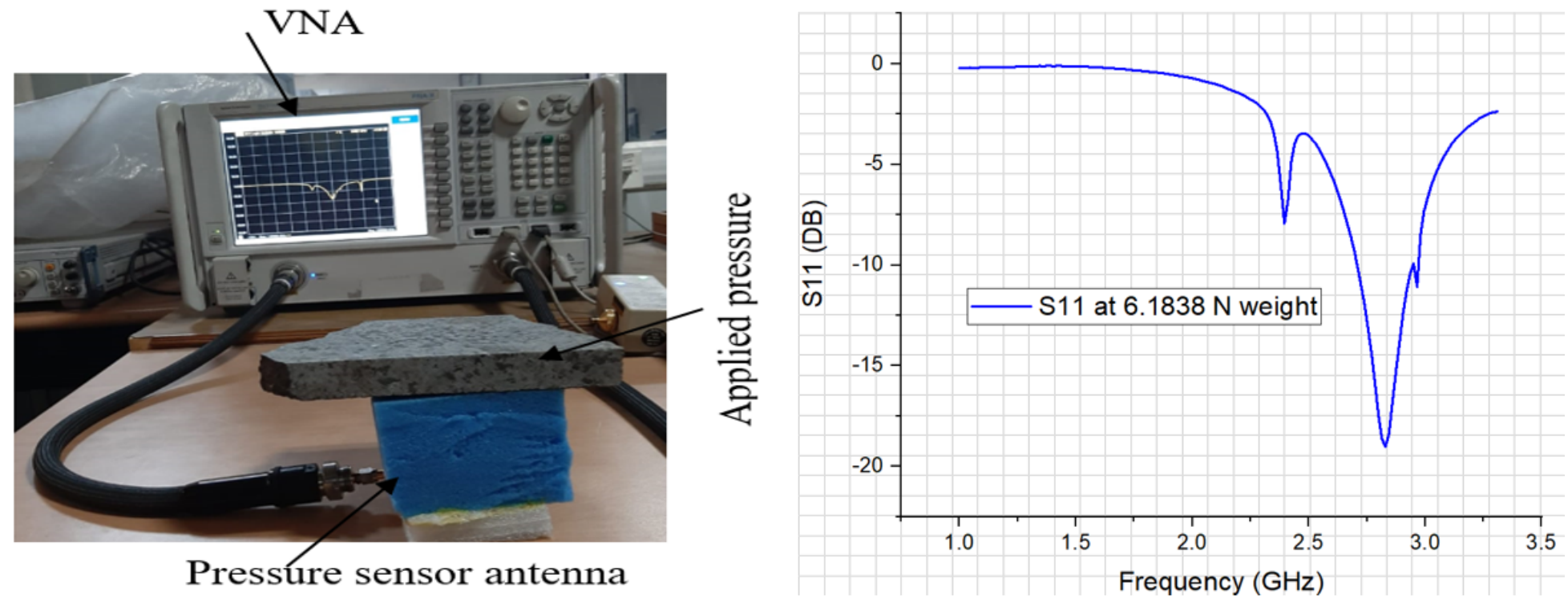

Figure 9

Experimental reflection coefficient when $6.1838 \mathrm{~N}$ weight load is applied

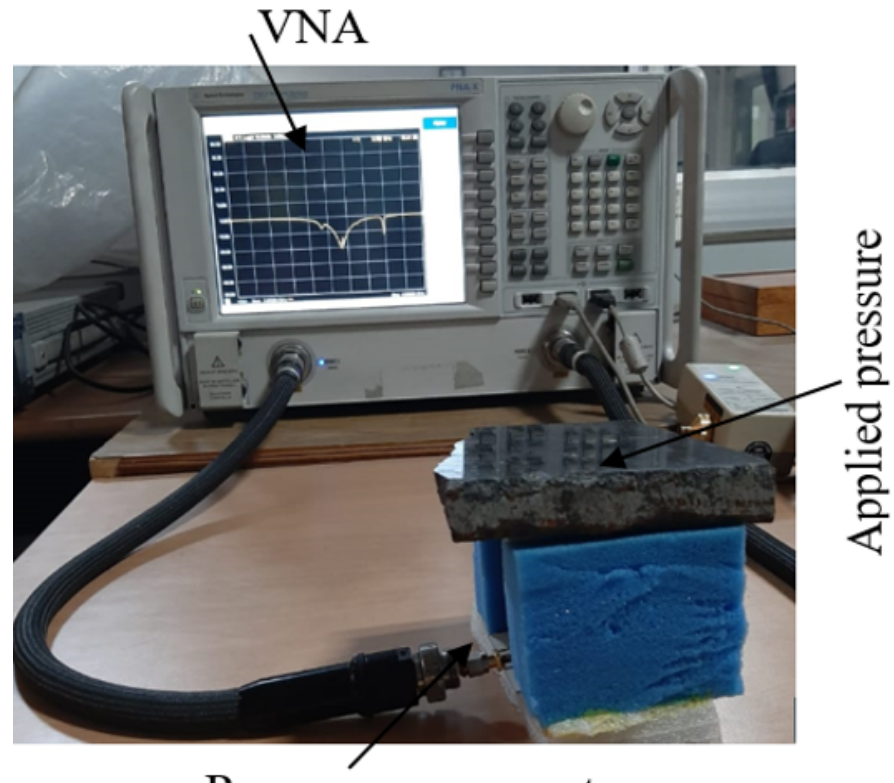

Pressure sensor antenna

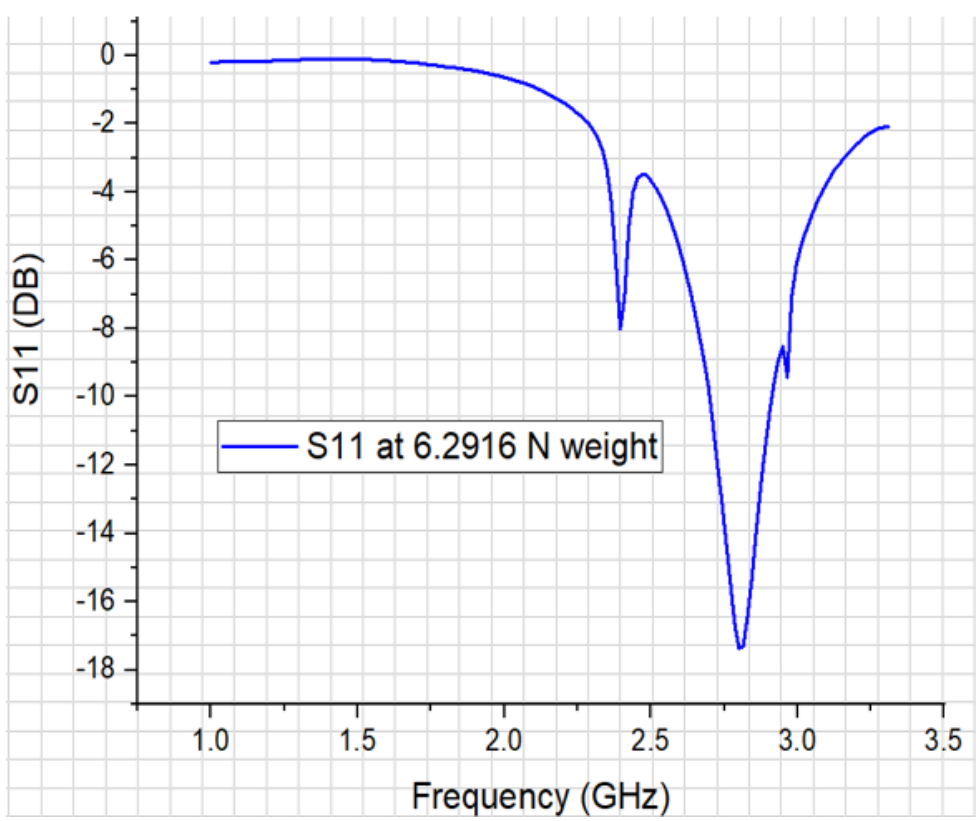

Figure 10

Experimental reflection coefficient when $6.2916 \mathrm{~N}$ weight load is applied 


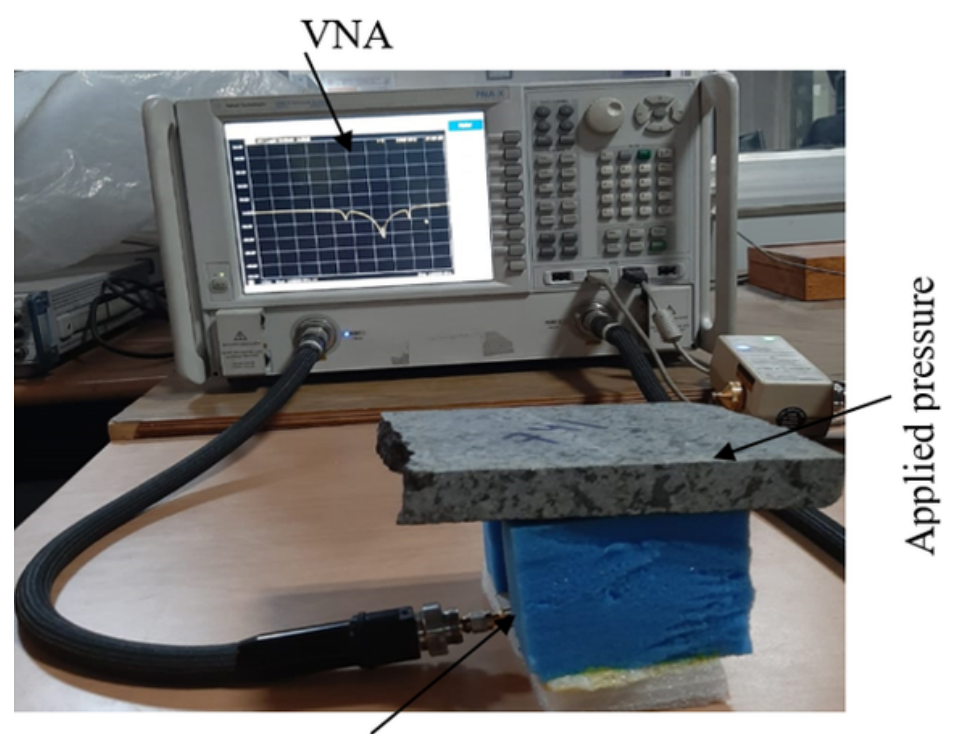

Pressure sensor antenna

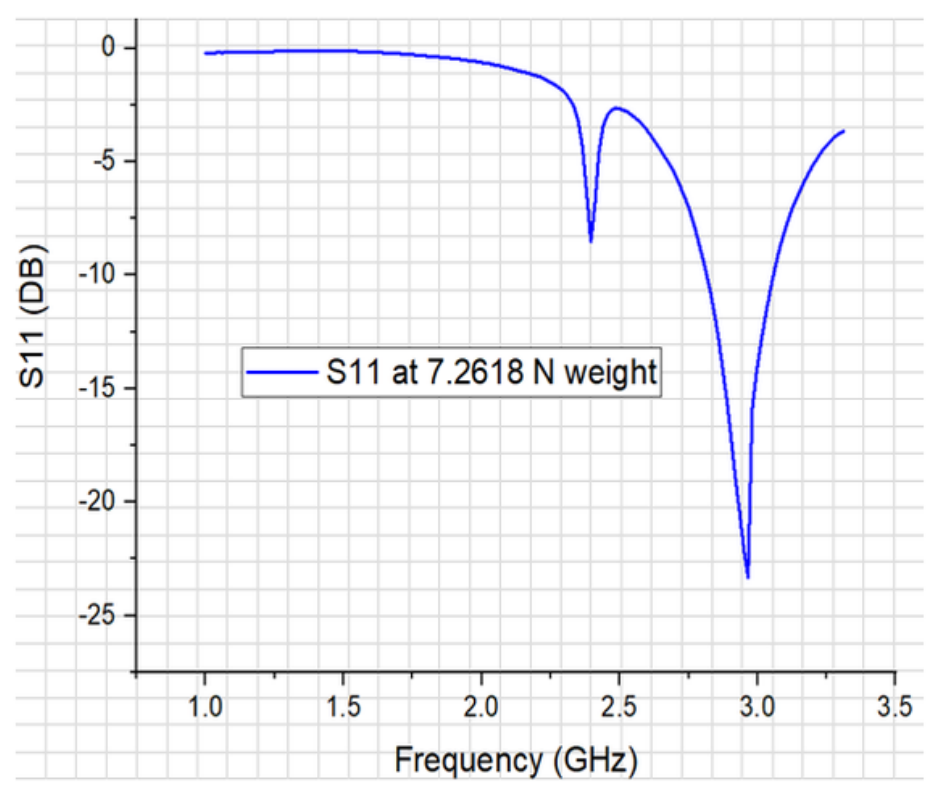

Figure 11

Experimental reflection coefficient when $7.2618 \mathrm{~N}$ weight load is applied

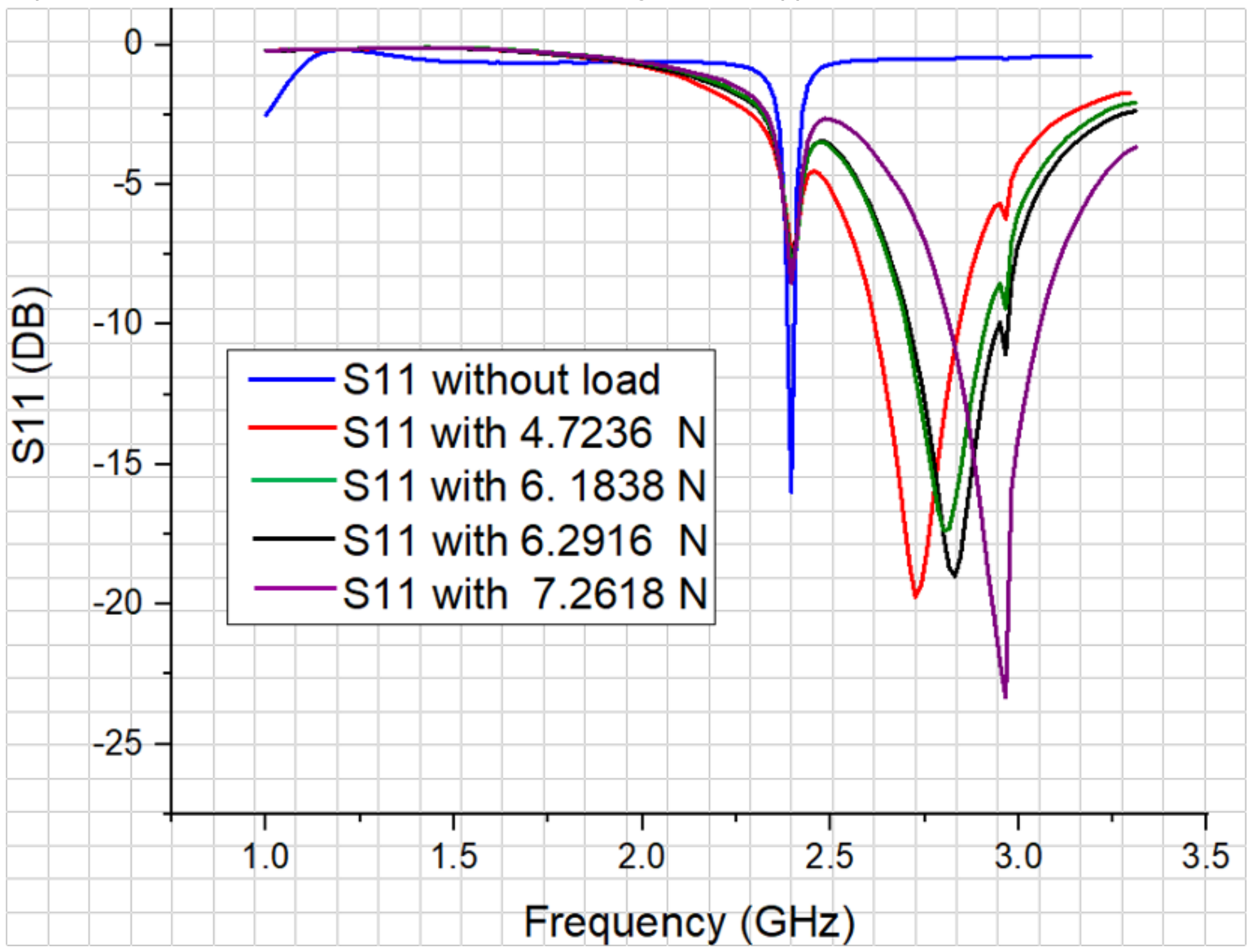


Figure 12

The experimental result comparisons of both without load applied and with a different load applied

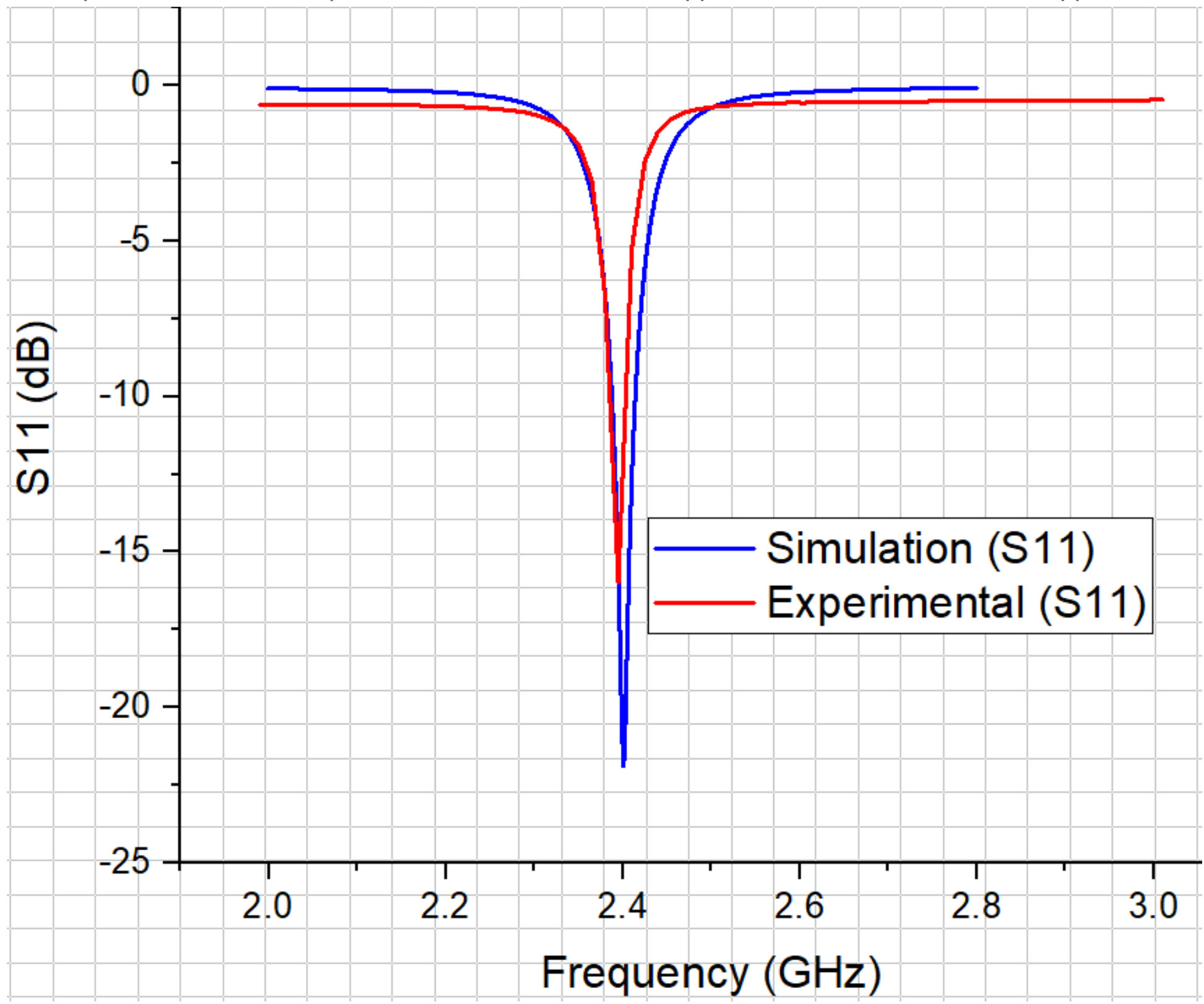

Figure 13

Compression between the simulation and experimental return loss of an antenna 